
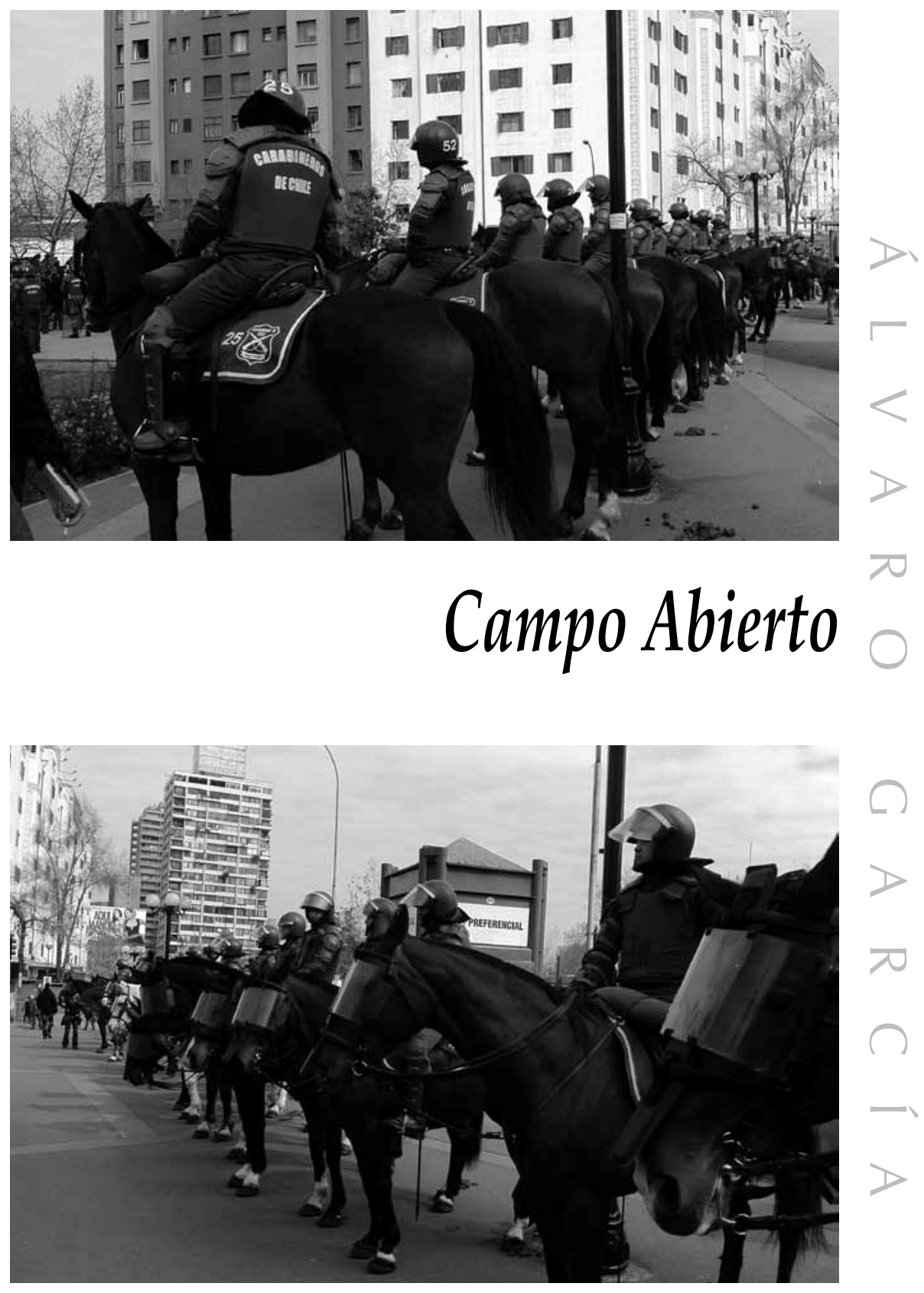

REVISTA NOMADÍAS

Noviembre 2011, Número 14, 173 - 175

\title{
De temblores y huellas de revolución
}

\author{
Bárbara Brito \\ Cuarto año Licenciatura en Filosofía \\ barbara.belen00@gmail.com
}

Pienso en cómo plasmar mi escrito de los mil y un acontecimientos-sentimientos que han irrumpido la historia chilena hoy, quebrando en un sentido la larga y tediosa transición a la democracia que llevaba 20 años andando, el último tiempo ya, sobre ruedas rechinantes. El vaso de agua en el que se encontraba la política nacional se removió intempestivamente, desde su base. El sismo ocurrido pareciera no acabar aquí, sino proyectarse extensamente forjando a su paso una juventud no sólo en lucha por las demandas educativas, sino principalmente antisistémica.

Mi mirada pretende dar vueltas en detalles de esta histórica movilización, vivencias particulares que reflejan a su vez transformaciones profundas en el "modo de ser" chileno, que revolucionan la moral católica hegemónica y los roles otorgados por género como herramientas para sostener y enraizar las desigualdades sociales esenciales al sistema capitalista.

Mi perspectiva será limitada a este punto: el cuestionamiento de hecho al rol social impuesto a la mujer, centrándome principalmente en el rol de madre. Sin embargo no pretendo abordarlo desde un ámbito académico, sino desde la vivencia personal, desde la experiencia que se ha situado en el centro del torbellino.

Una clave me parece que está en una importante frase, hoy emblema nacional: "somos la generación que nació sin miedo". Ese sentir temblar que opacó miradas durante 40 años, se traslada hoy a la Derecha y a la Concertación rompiendo con su seguridad inseguridad que se expresó también en los carabineros, bajando considerablemente el porcentaje de aprobación. Ese temer remueve hoy el régimen político, su mirada se acorta, se agacha ante cientos de miles de personas que asestan profundas heridas a los 
grandes pilares de la sociedad neoliberal fraguada en dictadura: la influencia de la iglesia católica y la estabilidad del régimen político, apedreamientos de iglesias y toma del congreso; ruptura parcial del conservadurismo impostado a lo sexual y baja en las encuestas del gobierno; madres trabajadoras que reafirmándose en su rol lo revolucionan transformando a sus hijos en compañeros de lucha y ellas mismas en luchadoras.

La ausencia y silencio de Michelle Bachelet en su figura de madre, que le dio el pase a la presidencia de Chile, sea quizás una de las razones de este tambaleo político, de esta inseguridad siempre asociada a lo femenino pero que hoy acecha a toda la clase dominante chilena. Sin embargo, lo más seguro es que, por el contrario, su ausencia sea la que se deba a esta explosión subterfugia de lo sexual que ha provocado la movilización en el rol de madre un transformación radical, barriendo con la figura de la "madre protectora".

Mientras "la madre Bachelet", como representación de la moral hegemónica, "brilla por su ausencia", desde el otro lado de la trinchera el temblor se transforma en fulgor incesante de lucha por los derechos más básicos como lo es la educación, en seguridad de un futuro sin miserias. Desde los colegios y universidades en toma, desde las marchas culturales y las barricadas en las calles, se transforma también el temblor en arma de amor contra la represión que se vuelca sin límites a los cientos de miles de jóvenes que están sosteniendo las tomas, luchando en las calles anónimamente, a ratos escondiéndose del ojo del poder Estatal que no dudará en ponerlos tras la rejas para cuidar los bolsillos del empresariado chileno. Son madres trabajadoras, que aparecen como luces en el camino, dispuestas a dar su vida, poner su cuerpo en defensa de sus hijos. Madres que no son parte de la generación que nació sin miedo: ellas temblaban cada vez que la habitación de sus hijos se encontraba vacía, temblaban en cada marcha, en cada protesta. Pero la ola las llevó, la generación que no vivió la dictadura les pegó un jalón. El temblor no sólo se convirtió en guerra incesante en defensa y lucha por sus hijos y sus demandas que, finalmente, se convirtieron en demandas de todos. La madre dejó de lado el constructo social dispuesto a disciplinar, encuadrar y encajar a sus hijos en esta sociedad de miserias. Reafirmándose en su rol, aún como madres, se convirtieron también en luchadoras superando el rol asignado de la madre protectora: pasaron a pelear por su propia liberación 
rompiendo con su propia invisibilización gestada en la entrega únicamente a un otro.

Esta sociedad se ha esmerado en imponer la maternidad. La mujer, nos dicen, está destinada biológicamente a ser madre. Este rol "natural" se justificaría además moralmente culminando en un conservadurismo que oprime la sexualidad de los sujetos. El trasfondo en realidad es sostener el sistema económico actual que, desgraciadamente, ha sido el punto inmune a la movilización en curso. El rol de madre es el culmine de la mujer como sujeto pasivo. Sin embargo la tendencia a quebrar con este rol que aporta al desarrollo y sostén del capitalismo es una cuestión viva y dinámica: cada vez que con mayor ahínco esta sociedad hunde en la miseria y opresión a mujeres trabajadoras e hijos, estos salen con más rabia a combatirlo. Parafraseando a Marx, el capitalismo crea sus propios sepultureros. Cuando sus hijos salieron a luchar, emigraron de casa para ir a asentarse a una toma, rompieron con su domesticación, con el domicilio, con lo dominante, decidieron jugar de lado del nomadismo y salir a defender a sus hijos. Esta defensa podría convertirse, contra los deseos de la iglesia católica, en una lucha contra la represión del Estado y la opresión de La Familia que la relega al hogar, en una muestra de liberación; en huella que podría superar las demandas por las que hemos luchado los protagonistas de esta movilización.

Esta reflexión se basa en grandes mujeres, compañeras de lucha: las apoderadas del A-90 que sostienen el colegio autogestionado de San Miguel o decenas de mujeres con las que me topé fuera y al interior de las comisarías mientras sus hijos o ellas mismas se encontraban detenidas, golpeadas y abusadas brutalmente por "los pacos culiaos". También en compañeras de lucha, madres de universidades y liceos. Con todas ellas hemos compartido duras batallas, difíciles encrucijadas políticas, análisis de la realidad nacional, combatividad en las calles, caceroleos... Y aunque no podemos generalizar, la lucha por la educación gratuita para todos sin duda abrió miles de flancos, mas uno de ellos podría cuestionar profundamente el orden en el que se establecen las relaciones sexuales y revolucionar profundamente los roles otorgados por género. 